\title{
A Research on Dissimilar Categorization of Basic Electrical Generator
}

\section{Boselin Prabhu $\mathrm{SR}^{1 *}$ and Balakumar $\mathbf{N}^{2}$}

${ }^{1}$ Department of Electrical and Electronics Engineering, Tamil Nadu College of Engineering, Coimbatore, Tamil Nadu, India ${ }^{2}$ Department of Electronics and Communication Engineering, SVS College of Engineering, Coimbatore, Tamil Nadu, India

The main objective of this paper is to study the basic electrical machine types and their applications. A DC machine can operate as a generator or motor. Generators and motors are the rotating machines. Based on the mode of operation, the mechanical power is converted in to electrical power and electrical power is converted in to mechanical power. A DC machine works on the basis of three modes of operation namely: Generating mode, Motoring mode and Braking mode. In first mode of operation, prime mover with mechanical power is converted in to electrical power. In the second mode of operation, the electrical power is converted in to mechanical power and this mechanical power is used to drive the mechanical load. In the third mode of operation, a machine can operate as a generator and electrical power is pumped back to the system for applying regenerative braking.

An electrical generator is a mechanism which converts mechanical energy into electrical energy. The energy conversion is based on the principle of electromagnetic induction. According to faraday's law of electromagnetic induction, whenever current carrying conductor is placed in a magnetic field, it will cut the flux lines thereby leading to create a force and generator tends to rotate [1].

Basically the DC machine could be classified on the basis of excitation namely, self-excited generator and separately excited generator. Separately-excited generators are those whose field magnets are energized from an independent external source of DC current. Selfexcited generators are those whose field magnets are energized by the current produced by the generators itself. There are three types of selfexcited generators which are named according to the manner by which their field coils are connected to the armature. Shunt wound: The field windings are connected in parallel with the armature conductors and the full voltage appears across the generator. Series Wound: The field windings are connected in series with the armature conductors. In this conncection the current flowing through the armature is equivalent to the line current. Compound Wound: It is a combination of a few series and a few shunt windings and can be connected in either short-shunt or long-shunt. In a compound generator, the shunt field winding has stronger than the series field winding. When series field winding aids the shunt field, generator is said to be commutatively-compounded. On the other side, if the series field winding opposes the shunt field, the generator is said to be differentially compounded [2].

Most electric power is produced and distributed as three-phase generator rather than single phase power for the below reasons: The cost of transmission is lesser than for the same voltage and power in a single phase, A three-phase generator has a $180 \%$ larger capacity than a single phase generator for the same physical size, Single-phase voltage and power is simply available from a three-phase system by simply tapping any two of the power leads and A three-phase AC generator is considered to produce three-phase AC power by constructing more coils in the stator around the rotor. The three coils are equally spaced at $120^{\circ}$ apart around and inside of the stator. The armature coils are wired so that the generator has three separate output voltages that differ in phase by 120 .

Air cooled generators are created in two basic configurations namely open ventilated and totally enclosed water to air cooled. In the open ventilated design, outside air is drawn straight from outside the unit over filters, passes through the generator and is discharged external to the generator $[1,2]$.

\section{References}

1. A hand book on basic dc electrical generator.

2. Theraja BL (1979) A Text book of Electrical Technology. S Chand and company Ltd, New Delhi, India.
*Corresponding author: Dr. Boselin Prabhu SR, Assistant Professor, Department of Electronics and Communication Engineering, SVS College of Engineering, Coimbatore, India, Tel: 9790100467; E-mail: eben4uever@gmail.com

Received February 09, 2017; Accepted February 16, 2017; Published February 23, 2017

Citation: Boselin Prabhu SR, Balakumar N (2017) A Research on Dissimilar Categorization of Basic Electrical Generator. J Electr Electron Syst 6: e119. doi:10.4172/2332-0796.1000e119

Copyright: @ 2017 Boselin Prabhu SR, et al. This is an open-access article distributed under the terms of the Creative Commons Attribution License, which permits unrestricted use, distribution, and reproduction in any medium, provided the original author and source are credited. 